\title{
Is High Serum LDL/HDL Cholesterol Ratio an Emerging Risk Factor for Sudden Cardiac Death? Findings from the KIHD Study
}

\author{
Setor K. Kunutsor ${ }^{1}$, Francesco Zaccardi ${ }^{2}$, Jouni Karppi ${ }^{3}$, Sudhir Kurl ${ }^{3}$ and Jari A. Laukkanen ${ }^{3,4}$ \\ ${ }^{1}$ School of Clinical Sciences, University of Bristol, Learning \& Research Building (Level 1), Southmead Hospital, Southmead Road, \\ Bristol, UK \\ ${ }^{2}$ Diabetes Research Centre, University of Leicester, Leicester, UK \\ ${ }^{3}$ Institute of Public Health and Clinical Nutrition, University of Eastern Finland, Kuopio, Finland \\ ${ }^{4}$ Department of Medicine, Central Finland Central Hospital, Jyväskylä, Finland
}

\begin{abstract}
Aim: Low-density lipoprotein cholesterol (LDL-c) and high-density lipoprotein cholesterol (HDL-c), which are components of total cholesterol, have each been suggested to be linked to the risk of sudden cardiac death (SCD). However, the relationship between LDL-c/HDL-c ratio and the risk of SCD has not been previously investigated. We aimed to assess the associations of LDL-c, HDL-c, and the ratio of LDL-c/HDL-c with the risk of SCD.

Methods: Serum lipoprotein concentrations were assessed at baseline in the Finnish Kuopio Ischemic Heart Disease prospective cohort study of 2,616 men aged 42-61 years at recruitment. Hazard ratios (HRs) (95\% confidence intervals $[\mathrm{CI}])$ were assessed.

Results: During a median follow-up of 23.0 years, a total of 228 SCDs occurred. There was no significant evidence of an association of LDL-c or HDL-c with the risk of SCD. In analyses adjusted for age, examination year, body mass index, systolic blood pressure, smoking, alcohol consumption, physical activity, years of education, diabetes, previous myocardial infarction, family history of coronary heart disease, and serum high sensitivity $\mathrm{C}$-reactive protein, there was approximately a two-fold increase in the risk of SCD (HR 1.94, 95\% CI 1.21-3.11; $p=0.006)$, comparing the top $(>4.22)$ versus bottom $(\leq 2.30)$ quintile of serum LDL-c/HDL-c ratio.

Conclusion: In this middle-aged male population, LDL-c or HDL-c was not associated with the risk of SCD. However, a high serum LDL-c/HDL-c ratio was found to be independently associated with an increased risk of SCD. Further research is warranted to understand the mechanistic pathways underlying this association.
\end{abstract}

Key words: Low-density lipoprotein cholesterol, High-density lipoprotein cholesterol, Sudden cardiac death

\section{Introduction}

Sudden cardiac death (SCD), generally defined as a sudden and unexpected death occurring within a short period of time after the onset of symptoms, accounts for $50 \%$ of all cardiovascular disease (CVD)related deaths ${ }^{1)}$. Given that SCD is a global public health burden ${ }^{2)}$, preventive strategies which are aimed

Address for correspondence: Jari A. Laukkanen, Institute of Public Health and Clinical Nutrition, University of Eastern Finland, P.O.Box 1627, FI-70211 Kuopio, Finland

E-mail: jariantero.laukkanen@uef.fi

Received: July 11, 2016

Accepted for publication: September 9, 2016 at modulation of potential risk factors is a desirable approach to decrease the risk of SCD at the population level. Low-density lipoprotein cholesterol (LDLc) plays a major role in the etiology of atherosclerosis $^{3)}$. A broad body of evidence shows LDL-c as the primary atherogenic lipoprotein ${ }^{4)}$ and high-density lipoprotein cholesterol (HDL-c) as the predominant anti-atherosclerotic lipoprotein ${ }^{5)}$. It is established that HDL-c is an independent protective risk factor for atherosclerotic $\mathrm{CVD}^{5,6)}$ and serum LDL-c as a causal risk factor for atherosclerotic $\mathrm{CVD}^{7-9)}$. Levels of these lipoproteins are now routinely measured in clinical practice for the screening of individuals with a high risk of CVD and being used as therapeutic targets for 
the primary and secondary prevention of $\mathrm{CVD}^{10,11)}$. Since approximately $80 \%$ of SCDs are attributable to underlying coronary heart disease (CHD) ${ }^{12}$ ), it follows that SCD and CHD share similar risk factors, which include the traditional cardiovascular risk factors such as hypercholesterolemia, diabetes, smoking, hypertension, and obesity ${ }^{13-15)}$. HDL-c and LDL-c (which are components of total cholesterol and established factors for $\mathrm{SCD}^{15)}$ ) have each been suggested to be linked to the risk of SCD, but the reports have mostly been inconsistent ${ }^{14,16}$. It has been suggested that an LDL-c/ HDL-c ratio is a better risk indicator for CVD than individual parameters ${ }^{17-20)}$. Thus, we hypothesized that the LDL-c/HDL-c ratio would relate to the risk of SCD rather than LDL-c or HDL-c alone. To the best of our knowledge, there has been no previous prospective evaluation of the association of LDL-c/HDL-c ratio with the risk of SCD. Our main objective was to evaluate the nature and magnitude of the prospective association of LDL-c/HDL-c with the risk of SCD in a population-based cohort of 2,616 apparently healthy men from eastern Finland. In subsidiary analyses, we also assessed the individual associations of serum LDL-c and HDL-c levels with the risk of SCD.

\section{Methods}

This report was conducted according to the STROBE (STrengthening the Reporting of OBservational studies in Epidemiology) guidelines for reporting observational studies in epidemiology ${ }^{21)}$.

\section{Study Population}

The Kuopio Ischemic Heart Disease (KIHD) risk factor study, a population-based prospective cohort study, was designed to investigate traditional and emerging risk factors for atherosclerotic cardiovascular outcomes in a population-based sample of men from eastern Finland. The study population was a representative sample of men living in the city of Kuopio and its surrounding rural communities who were 42-60 years of age at baseline examinations performed from March 1984 through December 1989. A total of 2,682 eligible men participated in this study. The current analysis is based on data obtained on 2,616 participants who had complete data on serum lipoproteins, relevant covariates, and SCD outcomes. The study was approved by the Research Ethics Committee of the University of Eastern Finland, and each participant provided written informed consent.

\section{Biochemical Measurements}

Subjects provided blood specimens for lipoprotein separation between 8:00 and 10:00 a.m. after hav- ing abstained from alcohol consumption for 3 days, from smoking for $12 \mathrm{~h}$, and after an overnight fast. After the subject had rested in the supine position for 30 min, blood was drawn using Terumo Venoject VT$100 \mathrm{PZ}$ vacuum tubes (Terumo Corp., Tokyo, Japan). No tourniquet was used. The main serum lipoprotein fractions consisting of very-low-density lipoprotein, LDL and HDL were separated within 3 days of blood sampling by a combination of ultracentrifugation and precipitation. The cholesterol content $(\mathrm{mmol} / \mathrm{L})$ of all lipoprotein fractions and serum triglycerides (TG) were determined via enzymatic methods (cholesterol CHOD-PAP method, Boehringer Mannheim, Mannheim, Germany ${ }^{22)}$. Blood glucose was measured via glucose dehydrogenase method (Merck, Darmstadt, Germany) after precipitation of proteins with trichloric acetic acid. Serum high sensitivity C-reactive protein (hs-CRP) was measured via the chemiluminescence-immunoassay method using Immulite 2000 analyzer (DPC, Los Angeles, USA).

\section{Assessment of Risk Markers}

Data on socio-demographics, physical measurements, medical history, and vascular risk factors have been previously described ${ }^{23)}$. Briefly, resting blood pressure was measured between 8:00 and 10:00 a.m. on the first examination day by a nurse using a randomzero mercury sphygmomanometer. The measuring protocol included, after a supine rest of $5 \mathrm{~min}$, three measurements in the supine position: one after $1 \mathrm{~min}$ of standing, and two in the sitting position with 5 min intervals. Alcohol consumption was assessed via a structured quantity-frequency method on drinking behavior over the previous 12 months. Prevalent CHD and myocardial infarction (MI) were ascertained via record linkage from the national computerized hospitalization registry, which covers every hospitalization in Finland. History of diabetes was defined as having a clinical diagnosis of diabetes and regular treatment with diet, oral hypoglycemic agents or insulin therapy, fasting plasma glucose of $\geq 7.0 \mathrm{mmol} / \mathrm{l}$, or according to self-reports. A subject was defined as a smoker if he had ever smoked on a regular basis and had smoked cigarettes, cigars, or a pipe within the past 30 days. The assessment of the use of lipid-lowering therapy over the follow-up period was based on the national social insurance institution registry.

\section{Definition of Follow-up Events}

Deaths that occurred by the end of 2010 were checked against the hospital documents, health centers, and death certificates. There were no losses to followup. A death was classified as SCD when it occurred within $24 \mathrm{~h}$ of the onset of symptoms, including non- 
Table 1. Baseline participant characteristics $(\mathrm{N}=2616)$

\begin{tabular}{|c|c|c|c|}
\hline & $\begin{array}{c}\text { Without SCD }(\mathrm{N}=2388) \\
\text { Mean }(\mathrm{SD}) \text { or } \%\end{array}$ & $\begin{array}{l}\text { With SCD }(\mathrm{N}=228) \\
\text { Mean }(\mathrm{SD}) \text { or } \%\end{array}$ & $P$-value \\
\hline \multicolumn{4}{|l|}{ Demographic characteristics } \\
\hline Age at survey (years) & $52.9(5.2)$ & $54.7(4.0)$ & $<0.001$ \\
\hline BMI $\left(\mathrm{kg} / \mathrm{m}^{2}\right)$ & $26.8(3.5)$ & $28.1(4.1)$ & $<0.001$ \\
\hline Years of education & $8.7(3.5)$ & $8.0(3.0)$ & 0.005 \\
\hline Physical activity (kcal/d) & $142.4(177.1)$ & $127.0(146.5)$ & 0.204 \\
\hline \multicolumn{4}{|l|}{ Medical history } \\
\hline $\mathrm{SBP}(\mathrm{mmHg})$ & $134(17)$ & $140(18)$ & $<0.001$ \\
\hline Alcohol consumption (g/week) & $74.3(137.3)$ & $93.5(134.0)$ & 0.044 \\
\hline Smokers & 31 & 45 & $<0.001$ \\
\hline Smoking (pack-years) ${ }^{*}$ & $7.9(16.0)$ & $14.5(20.9)$ & $<0.001$ \\
\hline Diabetics & 5 & 13 & $<0.001$ \\
\hline Previous MI & 6 & 28 & $<0.001$ \\
\hline CHD in family & 48 & 56 & 0.033 \\
\hline \multicolumn{4}{|l|}{ Laboratory data } \\
\hline Serum LDL cholesterol (mmol/L) & $4.02(1.02)$ & $4.26(1.01)$ & 0.001 \\
\hline Serum HDL cholesterol (mmol/L) & $1.30(0.30)$ & $1.23(0.31)$ & 0.001 \\
\hline Serum LDL-c/HDL-c ratio & $3.29(1.24)$ & $3.67(1.22)$ & $<0.001$ \\
\hline Serum hs-CRP (mmol/L) & $2.36(3.98)$ & $3.38(5.59)$ & $<0.001$ \\
\hline
\end{tabular}

witnessed cases when clinical and autopsy findings did not reveal a non-cardiac cause of sudden death ${ }^{24-26)}$. The sources of information were interviews, hospital documents, death certificates, autopsy reports, and medico-legal reports. The diagnostic classification of events was based on symptoms, electrocardiographic findings, cardiac enzyme elevations, autopsy findings $(80 \%)$, and history of CHD, together with the clinical and electrocardiographic findings of the paramedic staff. All CVD-related and CHD deaths were coded using the 9th or 10th International Classification of Diseases Revision.

\section{Statistical Methods}

Continuous variables were presented as means (standard deviations) and categorical variables as percentages. Means of the continuous variables were compared using ANOVA, and $\chi^{2}$ tests were used for categorical variables. Subjects were also classified according to fifths of the ratio of LDL-c/HDL-c. Hazard ratios (HR) and 95\% confidence intervals (CIs) for SCD, calculated by quintiles defined according to the baseline distribution of lipid fractions, were estimated using Cox proportional hazards model. Covariates were selected on the basis of their previously established roles as predictive factors ${ }^{27-29)}$. Two different sets of covariates were used: Model 1) age and examination year; Model 2) age, examination year, BMI, systolic blood pressure (SBP), smoking, alcohol consumption, physical activity, years of education, diabetes, previous MI, family history of CHD, and hs-CRP. Tests for statistical significance were two-sided, and differences with $p<0.05$ were considered statistically significant. SPSS software (version 19.0; SPSS, Inc., Chicago, IL, USA) was used for statistical analyses.

\section{Results}

\section{Baseline Characteristics}

Table 1 describes baseline characteristics of study participants. Men who died suddenly were older, had higher BMIs and SBPs, were more frequently smokers and consumed more alcohol, and were more likely to have had previous MIs and diabetes. They also had higher serum concentrations of LDL-c, hs-CRP, and LDL-c/HDL-c ratio, but lower concentrations of serum HDL-c. Participants in the highest fifth of the ratio of LDL-c/HDL-c $(>4.22)$ compared with those in the lowest fifth $(\leq 2.30)$ had higher BMIs, smoked more, but consumed less alcohol, had a higher prevalence of diabetes, and had previous MIs. Serum HDL-c level was lower and LDL-c level was higher 
Table 2. Demographic characteristics of the study population by quintiles of LDL-c/HDL-c ratio

\begin{tabular}{|c|c|c|c|c|c|c|}
\hline & \multicolumn{6}{|c|}{ Quintiles of LDL-c/HDL-c ratio } \\
\hline & $\begin{array}{c}\leq 2.30 \\
(n=523) \\
\text { mean }(\mathrm{SD}) \text { or } \%\end{array}$ & $\begin{array}{c}2.30-2.86 \\
(n=523) \\
\text { mean }(\mathrm{SD}) \text { or } \%\end{array}$ & $\begin{array}{c}2.87-3.44 \\
(n=524) \\
\text { mean }(\mathrm{SD}) \text { or } \%\end{array}$ & $\begin{array}{c}3.45-4.22 \\
(n=523) \\
\text { mean }(\mathrm{SD}) \text { or } \%\end{array}$ & $\begin{array}{c}>4.22 \\
(n=523) \\
\text { mean }(\mathrm{SD}) \text { or } \%\end{array}$ & $p$-value ${ }^{*}$ \\
\hline \multicolumn{7}{|l|}{ Demographic characteristics } \\
\hline Age at survey (years) & $52.7(5.3)$ & $52.8(5.3)$ & $53.2(5.2)$ & $53.3(4.8)$ & $53.3(4.9)$ & 0.116 \\
\hline BMI $\left(\mathrm{kg} / \mathrm{m}^{2}\right)$ & $26.0(3.6)$ & $26.9(3.9)$ & $26.9(3.2)$ & $27.5(3.8)$ & $27.2(3.1)$ & $<0.001$ \\
\hline Years of education & $8.9(3.6)$ & $8.9(3.5)$ & $8.4(3.2)$ & $8.4(3.4)$ & $8.6(3.4)$ & 0.015 \\
\hline Physical activity (kcal/d) & $156.4(170.5)$ & $131.4(140.2)$ & $147.8(200.9)$ & $138.4(189.1)$ & $131.5(165.8)$ & 0.089 \\
\hline \multicolumn{7}{|l|}{ Medical history } \\
\hline SBP (mmHg) & $133(18)$ & $135(17)$ & $134(16)$ & $135(17)$ & $135(17)$ & 0.365 \\
\hline Alcohol consumption (g/week) & $96.4(196.0)$ & $71.0(123.9)$ & $81.1(138.2)$ & $66.3(107.1)$ & $65.2(95.2)$ & 0.001 \\
\hline Smokers & 30 & 29 & 28 & 32 & 41 & $<0.001$ \\
\hline Smoking (pack-years) ${ }^{*}$ & $7.5(16.5)$ & $8.4(17.9)$ & $7.2(15.3)$ & $8.3(15.3)$ & $11.1(17.5)$ & 0.001 \\
\hline Diabetes & 4 & 6 & 4 & 9 & 6 & 0.002 \\
\hline Previous MI & 4 & 5 & 8 & 11 & 12 & $<0.001$ \\
\hline CHD in family & 47 & 45 & 50 & 52 & 51 & 0.152 \\
\hline \multicolumn{7}{|l|}{ Laboratory data } \\
\hline Serum LDL cholesterol (mmol/L) & $1.63(0.32)$ & $1.39(0.22)$ & $1.27(0.20)$ & $1.17(0.18)$ & $1.01(0.17)$ & $<0.001$ \\
\hline Serum HDL cholesterol $(\mathrm{mmol} / \mathrm{L})$ & $2.98(0.62)$ & $3.59(0.58)$ & $3.99(0.64)$ & $4.46(0.70)$ & $5.18(0.86)$ & $<0.001$ \\
\hline Serum hs-CRP (mmol/L) & $2.23(5.44)$ & $2.44(4.04)$ & $2.36(4.36)$ & $2.46(2.93)$ & $2.74(3.54)$ & 0.357 \\
\hline
\end{tabular}

BMI, body mass index; CHD, coronary heart disease; HDL, high-density lipoprotein; hs-CRP, high sensitivity C-reactive protein; LDL, low-density lipoprotein; MI, myocardial infarction; SD, standard deviation; SBP, systolic blood pressure; *, $p$-value for ANOVA; ${ }^{*}$, Pack-years denote the lifelong exposure to smoking, estimated as the product of years smoked and the number of tobacco products smoked

among those in the highest ratio of LDL-c/HDL-c (Table 2).

\section{Lipoproteins and the Risk of Sudden Cardiac Death}

During a median (interquartile range) follow-up time of $23.0(0.02-27.4)$ years, a total of 228 SCD cases occurred. In analyses adjusted for age and examination year, HRs of SCD comparing the top versus bottom fifths of LDL-c concentrations and LDL-c/ HDL-c ratio were 1.59 (95\% CI: $1.05-2.42 ; p=0.030$ ) and 2.67 (95\% CI: $1.68-4.23 ; p<0.001)$, respectively. Comparing the bottom versus top fifths of HDL-c levels, the corresponding risk was 2.08 (95\% CI: $1.35-3.19 ; p=0.001)$. In fully adjusted analyses, only LDL-c/HDL-c ratio remained significantly associated with the risk of SCD $(1.94,95 \%$ CI: $1.21-3.11 ; p=$ 0.006) (Table 3). In a subsidiary analysis which was limited to men with relevant information on serum lipoproteins, SCD outcomes, as well as information on lipid-lowering medication, the association remained consistent for LDL-c/HDL-c ratio and SCD risk in analysis that adjusted for several established risk factors and lipid-lowering medication. In separate analyses for CHD and CVD death, LDL-c/HDL-c ratio was significantly associated with each of these out- comes, 1.95 (95\% CI: $1.30-2.94 ; p=0.001)$ and 1.55 (95\% CI: $1.14-2.12 ; p=0.006)$, respectively. In a sensitivity analysis, we assessed the association between LDL-c/HDL-c ratio and SCD in subjects without a prevalent history of CHD. HRs comparing the top versus bottom fifths of LDL-c/HDL-c ratio were 2.06 (95\% CI: $1.21-3.48 ; p=0.007)$ and $1.79(95 \% \mathrm{CI}$ : $1.05-3.06 ; p=0.033)$, respectively, in analyses adjusted initially for age and examination year and further for established risk factors. To put the strength of the association of LDL-c/HDL-c ratio with SCD risk into context, direct comparisons were made to associations of serum triglycerides, non-HDL-c, TG/LDL-c ratio, and non-HDL-c/LDL-c ratio with SCD risk. There were no statistically significant associations of any of these lipid markers with the risk of SCD (Table 4).

\section{Discussion}

In this population-based study of middle-aged men, we observed an increased risk of SCD with a high LDL-c/HDL-c ratio. The association remained consistent when the analysis was restricted to men without a prevalent history of CHD. However, there was no significant association of SCD risk with HDL-c 
Table 3. Hazard ratios for sudden cardiac death by quintiles of serum lipoproteins and LDL-c/HDL-c ratio

\begin{tabular}{|c|c|c|c|c|c|c|}
\hline & \multicolumn{5}{|c|}{ Quintiles } & $p$-value \\
\hline LDL cholesterol (mmol/L) & $<3.18$ & $3.18-3.72$ & $3.73-4.18$ & $4.19-4.85$ & $>4.85$ & \\
\hline No. of cases/No. of participants & $35 / 525$ & $31 / 518$ & $48 / 524$ & $53 / 526$ & $61 / 523$ & \\
\hline $\operatorname{HR}(95 \% \mathrm{CI})^{\dagger}$ & Reference & $0.87(0.53-1.41)$ & $1.35(0.87-2.08)$ & $1.42(0.93-2.18)$ & $1.59(1.05-2.42)$ & 0.030 \\
\hline $\operatorname{HR}(95 \% \mathrm{CI})^{*}$ & Reference & $0.73(0.45-1.19)$ & $1.21(0.78-1.88)$ & $1.37(0.89-2.11)$ & $1.43(0.93-2.19)$ & 0.101 \\
\hline No. of cases/No. of participants & $32 / 532$ & $28 / 517$ & $54 / 525$ & $54 / 525$ & $60 / 517$ & \\
\hline $\operatorname{HR}(95 \% \mathrm{CI})^{\dagger}$ & Reference & $0.88(0.53-1.47)$ & $1.73(1.11-2.67)$ & $1.78(1.15-2.75)$ & $2.08(1.35-3.19)$ & 0.001 \\
\hline $\operatorname{HR}(95 \% \mathrm{CI})^{*}$ & Reference & $0.79(0.47-1.31)$ & $1.27(0.80-2.00)$ & $1.16(0.74-1.83)$ & $1.45(0.92-2.27)$ & 0.107 \\
\hline LDL-c/HDL-c ratio & $\leq 2.30$ & $2.30-2.86$ & $2.87-3.44$ & $3.45-4.22$ & $>4.22$ & \\
\hline No. of cases/No. of participants & $25 / 523$ & $36 / 523$ & $35 / 524$ & $65 / 523$ & $67 / 523$ & \\
\hline $\operatorname{HR}(95 \% \mathrm{CI})^{\dagger}$ & Reference & $1.37(0.82-2.28)$ & $1.32(0.79-2.21)$ & $2.59(1.63-4.11)$ & $2.67(1.68-4.23)$ & $<0.001$ \\
\hline
\end{tabular}

${ }^{\dagger}$ Adjusted for age and examination year.

*Adjusted for Model 1 plus BMI, systolic blood pressure, smoking, alcohol consumption, physical activity, years of education, diabetes, previous MI, CHD history in family and serum hs-CRP.

BMI, body mass index; CHD, coronary heart disease; CI, confidence interval; HDL, high-density lipoprotein; HR, hazard ratio; hs-CRP, high sensitivity C-reactive protein; LDL, low-density lipoprotein; MI, myocardial infarction

or LDL-c. Although total cholesterol (which has LDL-c and HDL-c as its components) is a major risk factor for $\mathrm{SCD}^{13,14)}$, prospective studies on the associations of its component lipoproteins have been limited and mostly conducted in individuals with pre-existing cardiometabolic disease, and the results have been inconsistent ${ }^{14,30)}$. Consistent with our results, it remains uncertain if LDL-c or HDL-c is independently associated with a future risk of SCD.

It is well established that the oxidative modification of LDL-c plays a key role in the pathogenesis of atherosclerosis ${ }^{3)}$. Oxidized LDL has a low affinity for macrophage scavenger receptors, and, thereby, oxidized LDL enters the blood circulation stimulating adhesion molecules and chemokines. Oxidized LDL can be taken up by macrophages through the scavenger receptors, leading to the formation of foam cells ${ }^{31}$. This cascade leads to initiation and progression of atherosclerosis in coronary arteries, which is an underlying cause of $\mathrm{SCD}^{32}$. In a postmortem study of SCDs, elevated LDL-c levels were shown to be correlated with the severity of coronary atherosclerosis ${ }^{33)}$. It has also been shown that plasma lipid and lipoprotein levels are significantly elevated in SCD cases ${ }^{16)}$. Among the LDL-c subclasses which differ in physiochemical properties and atherogenecity ${ }^{34)}$, small, dense LDL are regarded as more atherogenic than large LDL particles $^{35,36)}$. Non-HDL-c, which can easily be estimated from routine lipid panels, has been suggested to be a surrogate marker of small, dense LDL-c ${ }^{37)}$. In our study, however, we found no evidence of an associa- tion when LDL-c/HDL-c ratio was substituted for non-HDL-c/LDL-c ratio. For HDL-c, there is a growing body of evidence which supports the concept that the functional properties of HDL-c rather than circulating levels, may be more important in determining $\mathrm{CHD}$ risk $^{38)}$. Recent studies have shown that elevated HDL-c does not necessarily cause a decrease in the risk of $\mathrm{CHD}$. In the Framingham study, $40 \%$ of CHD events occurred in individuals with normal or elevated HDL levels ${ }^{5)}$. Very high levels of HDL-c have also been demonstrated not to be associated with the risk of vascular events ${ }^{39)}$. Indeed, the evidence suggests that enhancing HDL-c function rather than increasing its levels, is associated with clinical benefit ${ }^{11)}$.

Given that this is the first prospective study on the association of LDL-c/HDL-c ratio and the risk of SCD in a general population, it is difficult to compare our findings in the context of previous studies. Based on data from clinical trials ${ }^{40-42)}$, a high LDL-c/HDL-c ratio is associated with coronary plaque progression, whereas a decreased LDL-c/HDL-c ratio achieved by pharmacological interventions, may be associated with coronary plaque regression. Some studies have recommended that individuals with a high ratio of LDL-c/ HDL-c should commence treatment because of abnormal cholesterol levels ${ }^{43}$. A pooled analysis of data from four prospective randomized trials revealed a positive linear correlation between an index of LDL-c/HDL-c ratio and changes in coronary plaque volume $^{42)}$. In addition, an elevated LDL-c/HDL-c ratio has been suggested to be a predictor of coronary 
Table 4. Hazard ratios for sudden cardiac death by quintiles of serum triglycerides, non-HDL-c, TG/LDL-c ratio, and non-HDL-c/ LDL-c ratio

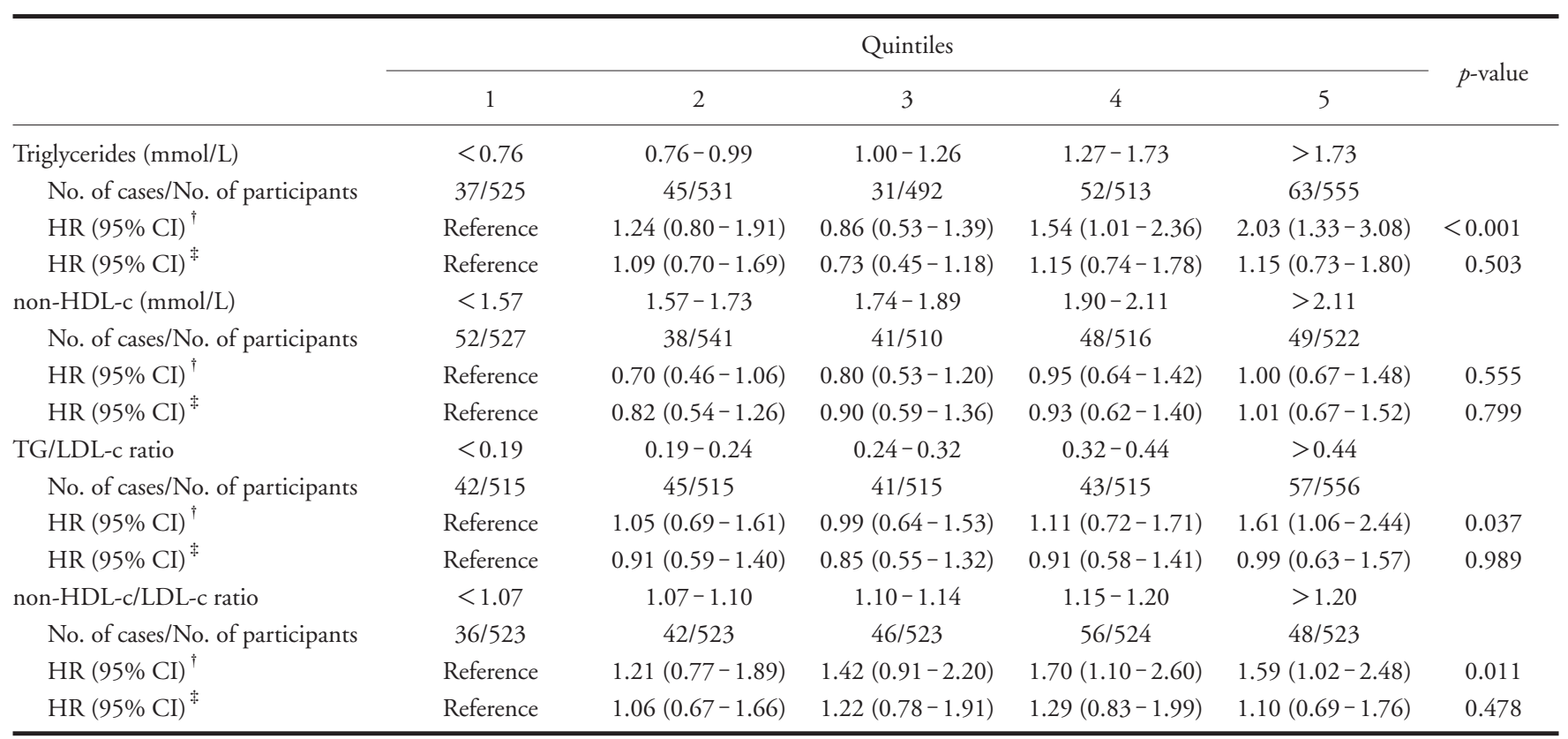

${ }^{\dagger}$ Adjusted for age and examination year.

\$Adjusted for Model 1 plus BMI, systolic blood pressure, smoking, alcohol consumption, physical activity, years of education, diabetes, previous MI, CHD history in family and serum hs-CRP.

BMI, body mass index; CHD, coronary heart disease; CI, confidence interval; HDL, high-density lipoprotein; HR, hazard ratio; hs-CRP, high sensitivity C-reactive protein; LDL, low-density lipoprotein; MI, myocardial infarction; TG, triglycerides

lipid-rich plaques and plaque vulnerability leading to an elevated SCD risk ${ }^{44,45)}$. Rupture of high-risk vulnerable plaques is considered to be the major pathway in the development of coronary thrombosis, which eventually leads to acute MI and SCD ${ }^{46)}$. Coronary heart disease is the most common pathology underlying $\mathrm{SCD}^{47,48)}$. However, in our study, the observed association of LDL-c/HDL-c ratio with the risk of SCD persisted when we restricted analysis to men without a history of CHD. Though the findings may partly reflect undiagnosed CHD, other pathways such as chronic inflammation may be involved. Further research is needed to help understand the mechanistic pathways of LDL-c/HDL-c ratio in the pathogenesis of SCD. Our findings demonstrate a clear and independent link between LDL-c/HDL-c ratio and SCD risk, which may have potential clinical implications. Assays for these lipoproteins are already being used in clinical practice to predict CVD risk in patients. Estimation of the ratio may have the potential to be used in the identification of individuals at high risk for SCD. However, further studies are needed to unequivocally establish this potential preventive strategy.

The strengths and limitations of the current study merit consideration. Strengths include its prospective population-based design, complete and long follow-up period, assessment of a comprehensive range of potential confounders, which enabled reliable assessments of the associations. Our representative sample makes it possible to generalize the observed results to male Caucasian populations, which was the primary focus of the study design; however, these results need to be replicated in female populations. The assessment of baseline clinical conditions by self-administered questionnaires is a limitation of the study. Further, we could not correct for regression dilution bias, which may have underestimated the observed associations, as we had only one-time assessment of lipid profiles, which may have changed during follow-up because of the probable changes in health habits or medication of participants over the time. Though many potential confounders were measured and carefully adjusted to ensure the validity of our key findings, there was still a potential for residual confounding owing to unmeasured risk factors.

In conclusion, the evidence suggests that a high LDL-c/HDL-c ratio, but not the individual lipoprotein components, is associated with an increased risk of SCD. Further studies are needed to replicate these associations and assess the mechanistic pathways underlying the relationships. 


\section{Acknowledgements}

We thank the staff of the Kuopio Research Institute of Exercise Medicine and the Research Institute of Public Health and University of Eastern Finland, Kuopio, Finland for the data collection in the study.

\section{Funding Sources}

This work was supported by the Academy of Finland, Helsinki, Finland; Finnish Medical Foundation, Helsinki, Finland; Finnish Cultural Foundation, Helsinki, Finland; and Jane and Aatos Erkko Foundation, Helsinki, Finland.

\section{Conflict of Interest}

The authors report no relationships that could be construed as a conflict of interest.

\section{References}

1) Straus SM, Bleumink GS, Dieleman JP, van der Lei J, Stricker BH and Sturkenboom MC: The incidence of sudden cardiac death in the general population. J Clin Epidemiol, 2004; 57: 98-102

2) Gillum RF: Geographic variation in sudden coronary death. Am Heart J, 1990; 119: 380-389

3) Steinberg D: The LDL modification hypothesis of atherogenesis: an update. J Lipid Res, 2009; 50 Suppl: S376381

4) Kannel WB and Wilson PW: Efficacy of lipid profiles in prediction of coronary disease. Am Heart J, 1992; 124: 768-774

5) Gordon T, Castelli WP, Hjortland MC, Kannel WB and Dawber TR: High density lipoprotein as a protective factor against coronary heart disease. The Framingham Study. Am J Med, 1977; 62: 707-714

6) Viles-Gonzalez JF, Fuster V, Corti R and Badimon JJ: Emerging importance of HDL cholesterol in developing high-risk coronary plaques in acute coronary syndromes. Curr Opin Cardiol, 2003; 18: 286-294

7) Goswami B, Rajappa M, Chakraborty B, Patra SK, Kumar S and Mallika V: Comparison of the various lipid ratios and indices for risk assessment in patients of myocardial infarction. Clin Biochem, 2012; 45: 445-449

8) Pauciullo P, Gentile M, Marotta G, Baiano A, Ubaldi S, Jossa F, Iannuzzo G, Faccenda F, Panico S and Rubba P: Small dense low-density lipoprotein in familial combined hyperlipidemia: Independent of metabolic syndrome and related to history of cardiovascular events. Atherosclerosis, 2009; 203: 320-324

9) Mabuchi H, Kita T, Matsuzaki M, Matsuzawa Y, Nakaya N, Oikawa S, Saito Y, Sasaki J, Shimamoto K, Itakura H and Trial JLSGJLI: Large scale cohort study of the relationship between serum cholesterol concentration and coronary events with low-dose simvastatin therapy in Japanese patients with hypercholesterolemia and coronary heart disease: secondary prevention cohort study of the Japan Lipid Intervention Trial (J-LIT). Circ J, 2002; 66: 1096-1100

10) Teramoto T, Sasaki J, Ueshima H, Egusa G, Kinoshita M, Shimamoto K, Daida H, Biro S, Hirobe K, Funahashi T, Yokote $\mathrm{K}$ and Yokode M: Executive summary of Japan Atherosclerosis Society (JAS) guideline for diagnosis and prevention of atherosclerotic cardiovascular diseases for Japanese. J Atheroscler Thromb, 2007; 14: 45-50

11) Ikenaga M, Higaki Y, Saku K and Uehara Y: High-density lipoprotein mimetics: a therapeutic tool for atherosclerotic diseases. J Atheroscler Thromb, 2016; 23: 385-394

12) Chugh SS, Jui J, Gunson K, Stecker EC, John BT, Thompson B, Ilias N, Vickers C, Dogra V, Daya M, Kron J, Zheng ZJ, Mensah G and McAnulty J: Current burden of sudden cardiac death: multiple source surveillance versus retrospective death certificate-based review in a large U.S. community. J Am Coll Cardiol, 2004; 44: 1268 1275

13) Jouven $X$, Desnos $M$, Guerot $C$ and Ducimetiere P: Predicting sudden death in the population: the Paris Prospective Study I. Circulation, 1999; 99: 1978-1983

14) Wannamethee G, Shaper AG, Macfarlane PW and Walker M: Risk factors for sudden cardiac death in middle-aged British men. Circulation, 1995; 91: 1749-1756

15) Albert CM, Chae CU, Grodstein F, Rose LM, Rexrode KM, Ruskin JN, Stampfer MJ and Manson JE: Prospective study of sudden cardiac death among women in the United States. Circulation, 2003; 107: 2096-2101

16) Nakajima K, Nakajima $Y$, Takeichi $S$ and Fujita $M Q$ : Plasma remnant-like lipoprotein particles or LDL-C as major pathologic factors in sudden cardiac death cases. Atherosclerosis, 2008; 198: 237-246

17) Kannel WB: Risk stratification of dyslipidemia: insights from the Framingham Study. Curr Med Chem Cardiovasc Hematol Agents, 2005; 3: 187-193

18) Ingelsson E, Schaefer EJ, Contois JH, McNamara JR, Sullivan L, Keyes MJ, Pencina MJ, Schoonmaker C, Wilson PW, D'Agostino RB and Vasan RS: Clinical utility of different lipid measures for prediction of coronary heart disease in men and women. JAMA, 2007; 298: 776-785

19) Hsia SH, Pan D, Berookim P and Lee ML: A populationbased, cross-sectional comparison of lipid-related indexes for symptoms of atherosclerotic disease. Am J Cardiol, 2006; 98: 1047-1052

20) Kastelein JJ, van der Steeg WA, Holme I, Gaffney M, Cater NB, Barter P, Deedwania P, Olsson AG, Boekholdt SM, Demicco DA, Szarek M, LaRosa JC, Pedersen TR, Grundy SM, Group TNTS and Group IS: Lipids, apolipoproteins, and their ratios in relation to cardiovascular events with statin treatment. Circulation, 2008; 117: 3002-3009

21) von Elm E, Altman DG, Egger M, Pocock SJ, Gotzsche PC and Vandenbroucke JP: The Strengthening the Reporting of Observational Studies in Epidemiology (STROBE) statement: guidelines for reporting observational studies. J Clin Epidemiol, 2008; 61: 344-349

22) Salonen JT, Salonen R, Seppanen K, Rinta-Kiikka S, Kuukka M, Korpela H, Alfthan G, Kantola M and Schalch W: Effects of antioxidant supplementation on platelet function: a randomized pair-matched, placebo- 
controlled, double-blind trial in men with low antioxidant status. Am J Clin Nutr, 1991; 53: 1222-1229

23) Salonen JT, Nyyssonen K, Korpela H, Tuomilehto J, Seppanen $\mathrm{R}$ and Salonen R: High stored iron levels are associated with excess risk of myocardial infarction in eastern Finnish men. Circulation, 1992; 86: 803-811

24) Kurl S, Makikallio TH, Rautaharju P, Kiviniemi V and Laukkanen JA: Duration of QRS complex in resting electrocardiogram is a predictor of sudden cardiac death in men. Circulation, 2012; 125: 2588-2594

25) Laukkanen JA, Makikallio TH, Rauramaa R, Kiviniemi V, Ronkainen $\mathrm{K}$ and Kurl S: Cardiorespiratory fitness is related to the risk of sudden cardiac death: a populationbased follow-up study. J Am Coll Cardiol, 2010; 56: 1476-1483

26) Kunutsor SK, Khan H and Laukkanen JA: gamma-Glutamyltransferase and risk of sudden cardiac death in middle-aged Finnish men: A new prospective cohort study. J Am Heart Assoc, 2016; 5:

27) Ray K, Wainwright NW, Visser L, Witteman J, Breteler M, Ambegaonkar B, Hofman A, Stricker B, Wareham N, Khaw KT and Sandhu M: Changes in HDL cholesterol and cardiovascular outcomes after lipid modification therapy. Heart, 2012; 98: 780-785

28) Farrell SW, Finley CE and Grundy SM: Cardiorespiratory fitness, LDL cholesterol, and CHD mortality in men. Med Sci Sports Exerc, 2012; 44: 2132-2137

29) King DE, Mainous AG, 3rd, Matheson EM and Everett CJ: Impact of healthy lifestyle on mortality in people with normal blood pressure, LDL cholesterol, and C-reactive protein. Eur J Prev Cardiol, 2013; 20: 73-79

30) Suarez GA, Clark VM, Norell JE, Kottke TE, Callahan MJ, O'Brien PC, Low PA and Dyck PJ: Sudden cardiac death in diabetes mellitus: risk factors in the Rochester diabetic neuropathy study. J Neurol Neurosurg Psychiatry, 2005; 76: 240-245

31) Yoshida $\mathrm{H}$ and Kisugi R: Mechanisms of LDL oxidation. Clin Chim Acta, 2010; 411: 1875-1882

32) Myerburg RJ, Kessler KM, Bassett AL and Castellanos A: A biological approach to sudden cardiac death: structure, function and cause. Am J Cardiol, 1989; 63: 1512-1516

33) Takeichi S, Yukawa N, Nakajima Y, Osawa M, Saito T, Seto Y, Nakano T, Saniabadi AR, Adachi M, Wang T and Nakajima K: Association of plasma triglyceride-rich lipoprotein remnants with coronary atherosclerosis in cases of sudden cardiac death. Atherosclerosis, 1999; 142: 309315

34) Rizzo M and Berneis K: Small, dense low-density-lipoproteins and the metabolic syndrome. Diabetes Metab Res Rev, 2007; 23: 14-20

35) Packard C, Caslake M and Shepherd J: The role of small, dense low density lipoprotein (LDL): a new look. Int J Cardiol, 2000; 74 Suppl 1: S17-22

36) Austin MA, Breslow JL, Hennekens CH, Buring JE, Willett WC and Krauss RM: Low-density lipoprotein subclass patterns and risk of myocardial infarction. JAMA, 1988; 260: 1917-1921

37) Moriyama K and Takahashi E: Non-HDL Cholesterol is a more superior predictor of small-dense LDL cholesterol than LDL cholesterol in Japanese subjects with TG levels $400 \mathrm{mg} / \mathrm{dL}$. J Atheroscler Thromb, 2016;
38) White CR, Datta G, Mochon P, Zhang Z, Kelly O, Curcio C, Parks D, Palgunachari M, Handattu S, Gupta H, Garber DW and Anantharamaiah GM: Vasculoprotective effects of apolipoprotein mimetic peptides: an evolving paradigm in Hdl therapy (Vascular Disease Prevention, In Press.). Vasc Dis Prev, 2009; 6: 122-130

39) Hirata A, Okamura T, Sugiyama D, Kuwabara K, Kadota A, Fujiyoshi A, Miura K, Okuda N, Ohkubo T, Okayama A, Ueshima $\mathrm{H}$ and Group NDR: The relationship between very high levels of serum high-density lipoprotein cholesterol and cause-specific mortality in a 20 -year follow-up study of Japanese general population. J Atheroscler Thromb, 2016; 23: 800-809

40) Schoenhagen P, Tuzcu EM, Apperson-Hansen C, Wang C, Wolski K, Lin S, Sipahi I, Nicholls SJ, Magyar WA, Loyd A, Churchill T, Crowe T and Nissen SE: Determinants of arterial wall remodeling during lipid-lowering therapy: serial intravascular ultrasound observations from the Reversal of Atherosclerosis with Aggressive Lipid Lowering Therapy (REVERSAL) trial. Circulation, 2006; 113: 2826-2834

41) Nissen SE, Nicholls SJ, Sipahi I, Libby P, Raichlen JS, Ballantyne CM, Davignon J, Erbel R, Fruchart JC, Tardif JC, Schoenhagen P, Crowe T, Cain V, Wolski K, Goormastic M, Tuzcu EM and Investigators A: Effect of very high-intensity statin therapy on regression of coronary atherosclerosis: the ASTEROID trial. JAMA, 2006; 295: 1556-1565

42) Nicholls SJ, Tuzcu EM, Sipahi I, Grasso AW, Schoenhagen P, Hu T, Wolski K, Crowe T, Desai MY, Hazen SL, Kapadia SR and Nissen SE: Statins, high-density lipoprotein cholesterol, and regression of coronary atherosclerosis. JAMA, 2007; 297: 499-508

43) Packard CJ, Ford I, Robertson M, Shepherd J, Blauw GJ, Murphy MB, Bollen EL, Buckley BM, Cobbe SM, Gaw A, Hyland M, Jukema JW, Kamper AM, Macfarlane PW, Perry IJ, Stott DJ, Sweeney BJ, Twomey C, Westendorp RG and Group PS: Plasma lipoproteins and apolipoproteins as predictors of cardiovascular risk and treatment benefit in the PROspective Study of Pravastatin in the Elderly at Risk (PROSPER). Circulation, 2005; 112: 3058-3065

44) Kimura T, Itoh T, Fusazaki T, Matsui H, Sugawara S, Ogino Y, Endo H, Kobayashi K and Nakamura M: Lowdensity lipoprotein-cholesterol/high-density lipoproteincholesterol ratio predicts lipid-rich coronary plaque in patients with coronary artery disease--integrated-backscatter intravascular ultrasound study. Circ J, 2010; 74: 13921398

45) Kim JH, Jeong MH, Hong YJ, Lee KH, Kim IS, Choi YH, Lee MG, Park KH, Sim DS, Kim JH, Ahn Y, Cho JG, Park JC and Kang JC: Low density lipoprotein-cholesterol/high density lipoprotein-cholesterol ratio predicts plaque vulnerability in patients with stable angina. Korean Circ J, 2012; 42: 246-251

46) Yang F and Patterson RP: A novel impedance-based tomography approach for stenotic plaque detection: a simulation study. Int J Cardiol, 2010; 144: 279-283

47) Hayashi M, Shimizu W and Albert CM: The spectrum of epidemiology underlying sudden cardiac death. Circ Res, 2015; 116: 1887-1906 
48) Authors/Task Force M, Priori SG, Blomstrom-Lundqvist C, Mazzanti A, Blom N, Borggrefe M, Camm J, Elliott PM, Fitzsimons D, Hatala R, Hindricks G, Kirchhof P, Kjeldsen K, Kuck KH, Hernandez-Madrid A, Nikolaou N, Norekval TM, Spaulding C and Van Veldhuisen DJ: 2015 ESC Guidelines for the management of patients with ventricular arrhythmias and the prevention of sud- den cardiac death: The Task Force for the Management of Patients with Ventricular Arrhythmias and the Prevention of Sudden Cardiac Death of the European Society of Cardiology (ESC)Endorsed by: Association for European Paediatric and Congenital Cardiology (AEPC). Eur Heart J, 2015 Aug 29. pii: ehv316 